\author{
E-ISSN: 2469-6501 \\ VOL: 7, ISSUE: 10 \\ October/2021 \\ DOI: http://dx.doi.org/10.33642/ijbass.v7n10p2 \\ (c) (i) \\ https://creativecommons.org/licenses/by/4.0/
}

\title{
Key Theoretical Principles to Implement the Student-Centered Learning and Teaching Process
}

\author{
Prof. Elena Intorcia \\ Department of Law, Economics, Management and Quantitative Methods (DEMM) \\ Department of Engineering (DING) \\ University of Sannio, Benevento, Italy \\ Email: elenaint@unisannio.it \\ Italy
}

\author{
Prof. Erricoberto Pepicelli* \\ Department of Law, Economics, Management and Quantitative Methods (DEMM) \\ Department of Engineering (DING) \\ University of Sannio, Benevento, Italy \\ Email: pepicelli@unisannio.it \\ Italy \\ *E.Pepicelli, previously teacher of English at the University of Sannio since 1998, is now a \\ member of the Examination Board at the Department of Engineering after retiring in 2020.
}

ABSTRACT

The starting point of this article is the United Nations Agenda 2030, an outstanding international project, with a special emphasis on Goal 4 that focuses on providing "Quality Education», an objective that the current global pandemic is making more and more challenging. All the educational agencies, putting academia first, should pursue the aims of Goal 4, setting up a well-established plan with clearly stated objectives. Starting from the controversial principle that «learning is impeded by teaching», some relevant pedagogical practices are examined, such as Retrieval Practice, CLIL, and Microlanguages. Nevertheless, the core of this article deals with some pairs and triples of key theoretical principles, besides some basic theoretical areas, any educator should be familiar with and apply during her/his approach to the learning/teaching process.

\section{Keywords: UN Agenda 2030; Goal 4; learning; teaching; theoretical principles; theoretical areas}

\section{Introduction}

In 2015, 195 nations agreed with the United Nations that they could change the world for the better and to this aim they set up the Agenda 2030, an outstanding international project with special attention also to the field of education, ensuring inclusive and equitable education and promoting lifelong learning opportunities. This aim could be accomplished by bringing together their respective governments, businesses, media, institutions of higher education, and local nongovernmental organizations (NGOs) to improve the lives of the people in their countries by the year 2030 through the implementation of 17 Sustainable Development Goals (SDGs), starting from «No Poverty» and ending up with «Partnership for the Goals» with Goal 4 addressing the need to provide «Quality Education».

Last checks for the level of implementation of the 17 Goals were carried out in 2020. The World Top 20 Project's Education Rankings, in particular, focuses on the top 20 nations' progress and digression in improving education in their countries, equally looking at how this is affecting their economic growth and impacting their social conditions. This in-between check has identified Denmark as the top country, while in 2019 it had ranked third. Denmark has captured the 2020 spot turning into one of the most progressive and successful countries tackling the Covid-19 pandemic. While other countries panicked, Denmark leaders decided to take a more measured approach to protect their school staff and provide education services to their students. Some data related to this country identify as «progress» an early childhood enrolment rate; «digress», a High School graduation rate; «strengths», adult illiteracy levels, and, regarding «weaknesses», access to the Internet.

Still, during a global pandemic, it is clear that almost every country is facing enormous challenges, and progress in key areas is slow or regressing, as shown by the recent Sustainable Development Goals Report (2020). Global Human Development, measured as a combination of the world's education, health, and living standards, was expected to decline in 2020 for the first time since measurements began in 1990.

A keyword from the previous statement, by now widely used perhaps even overused is sustainability.

It is crucial to capitalize on this complex concept. A clear definition of sustainability comes from the UN World Commission on Environment and Development: «Sustainable development is a development that meets the needs of the present without compromising the ability of future generations to meet their own needs». To meet this aim it is necessary to strengthen the means of implementation and to revitalize the global partnership for sustainable development.

\section{Educational objectives}

All the educational agencies, putting academia first, should pursue the aims of Goal 4, Quality Education, through appropriate strategies and techniques, activating the right processes within the framework of sustainable development. To this purpose, between learners and teacher, a tri- 


\title{
International Journal of Business and Applied Social Science (IJBASS)
}

\author{
E-ISSN: 2469-6501 \\ VOL: 7, ISSUE: 10 \\ October/2021 \\ DOI: http://dx.doi.org/10.33642/ijbass.v7n10p2 \\ (c) (7) \\ https://creativecommons.org/licenses/by/4.0/
}

dimensional or triangular/circular communication should be activated and encouraged as much as possible: teacher-student, student-student, student-teacher.

Similarly, all educational institutions should have a well-established plan with clearly stated objectives shared among all the stakeholders. In particular, the university should pursue, Michael Oakshott (1972) claims, three main objectives: 1 concentrate on the student as a person; 2 increase her/his knowledge; 3 prepare her/him for a democratic society, beyond immediate utilitarian objectives. ${ }^{1}$ This is not an easy job, because students want, first of all, to pass the exams and, then, graduate. So, it is up to the teachers to accommodate both these objectives with the formative, medium- and long-term ones. Students should be equipped also with skills and competencies to be spent for success in their future life, enabling them to proudly claim, at the end of their course of studies: "We know where we go, we have a plan".

\section{Retrieval Practice}

Henry Widdowson adds further highly authoritative support to the Student-Centered Learning Teaching Process (SCLTP), when he claims that «language learning is impeded by teaching». ${ }^{2}$ To this aim, it is undoubtedly useful to examine Retrieval Practice, a strategy which appears to be clear and convincing at the same time. Here are its most relevant assumptions.

Most of the teaching focuses on getting information into the learner's head using various strategies, hoping it might last longer. Retrieval Practice - also called by cognitive scientists «the testing effect» - is an active process and strategy, consisting in deliberately bringing information to mind: recalling information enhances and boosts learning in so far as by so doing, we exercise or strengthen our memory, even identifying gaps in our learning. Conversely, when learners learn something by heart, it does not last long, as this just leads to short-term learning. As a matter of a fact, after a little while they forget most of it quite easily because when information comes easily to mind, it easily tends to be forgotten.

There is an important assumption about memory: when information comes to mind easily and fluently, we have learned successfully. Much to our surprise, however, memory researchers (Nora S. Newcombe 2010) have demonstrated that the opposite is true: when information comes to mind easily and feels fluent, it is easy to forget. Instead, learning through effort lasts longer: it is precisely this struggle or challenge that improves our memory and learning. Pulling information out of learners' minds through the process of retrieval dramatically improves learning. Although progress might seem slow, longterm learning is favoured. ${ }^{3}$

\section{CLIL (Content and Language Integrated Learning)}

${ }^{1}$ Oakeshott, M., 1972, "Education: the Engagement and its Frustration" in Fuller, T., (ed.) (1989) The Voice of Liberal Learning, New Haven and London: Yale University Press.

${ }^{2}$ Widdowson, H. 2019, "Disciplinarity and Disparity in Applied Linguistics" in Wright, C. et al., Voices, and Practices in Applied Linguistics: Diversifying a Discipline, York: White Rose University Press.
Another mode, extremely important in the learning/teaching process, has become quite popular lately: CLIL (Content and Language Integrated Learning). Many universities and schools are applying CLIL pursuing a twofold objective: to improve a foreign/second language while learning a new subject. This is not new. Although it was theorized in the last decade or so, it was previously widespread in the areas where two languages were officially accepted or predominant: English and Spanish in some U.S. States; Italian and German in Alto Adige; French and Italian in Valle D'Aosta in Italy; German, French and/or Italian in Switzerland, without forgetting India, where English is used as the language of instruction and communication. In these circumstances, many or all the subjects at universities may be presented through the second language. There are, instead, contexts with a mother tongue and a foreign language like English in the rest of Italy, France, or Germany. Here pedagogists and other experts have deepened their studies and have come out with CLIL.

According to the European Commission, CLIL can provide effective opportunities for learners. This approach involves learning subjects such as history, geography, managerial skills/concepts or others, through an additional language. It can be very successful in enhancing the learning of languages and other subjects and helping children develop a positive attitude towards themselves as language learners. The European Commission has therefore decided to promote the training of teachers "to enhance the language competencies in general, to promote the teaching of non-linguistic subjects in foreign/second languages".

Some of the most significant objectives of CLIL (Coyle et al., 2010, and Lorenzo et al., 2011) include:

- improve the educational system as a whole;

- allow students to achieve the appropriate level of academic performance in the target subjects and graduate;

- improve students' proficiency in both their mother tongue/the target language and the subjects dealt with, attaching the same importance to both, and, in so doing, developing an intercultural understanding;

- develop social and thinking skills; also encouraging students to develop life skills, including the ability to think critically, to be creative, to communicate, and collaborate.

- learn subjects such as history, geography, managerial skills, or others.

- prepare students also for the globalized world;

- promote the learning of a more extensive and varied vocabulary, with emphasis on microlanguage (having a real context to learn the language in, students are often more motivated to do so);

- encourage a deeper level of assimilation as students are repeatedly exposed to the same language and practice its functions; besides, they need to produce and recall information in this language. 


\author{
E-ISSN: 2469-6501 \\ VOL: 7, ISSUE: 10 \\ October/2021 \\ DOI: http://dx.doi.org/10.33642/ijbass.v7n10p2

A science course, for example, can be taught to students through English so that they will not only improve their English competence and performance while learning about science, but they will also gain relevant vocabulary, especially microlanguage, along with language skills.

CLIL can work for students of any age, all the way from primary level to university and beyond if designed with the learners' needs in mind. It is widely implemented in some universities, also in Italy, when professors have adequate competence in the foreign language, usually English.

On the other hand, the challenges of CLIL are many. Teachers are required to possess specific competencies; they must also structure their classes carefully so that students understand the content of the lesson/lecture, as well as the language through which the information is being conveyed. In other words, when it comes to classroom management, educators need to be very aware of individual students' understanding and progress. It is important to have a strategy in place when applying CLIL in courses. One of the key things to remember is that the language and subject content are given equal weight and that it should not be treated as a language class nor a subject class simply taught in a foreign/second language. Continuous assessment and evaluation are required too.

\section{Microlanguages}

A positive consequence of CLIL is the attention to be devoted to the subject-specific vocabulary or microlanguage of the target subject, which comes out as soon as anyone starts dealing with it. Every subject has a vocabulary that students need to understand, learn and be able to use in their language production both through speaking and writing to make sense of the content being learned; namely, it is through the correct use of subject-specific vocabulary that a person can be defined 'educated'.

It is highly helpful to be able to use clues to single out the meaning of words. The current research suggests that skilled adult readers routinely use morphological knowledge to recognize words (Rastle, 2018). Here are some examples:

\begin{tabular}{|l|l|l|l|}
\hline \multirow{2}{*}{ Subject } & Word & Morpheme & Related words \\
\hline \multirow{3}{*}{ Mathematics } & millimeter & milli (thousand) & millilitre, milligram \\
\cline { 2 - 4 } & polygon & poly (many) & polygamy, polynomial \\
\hline \multirow{2}{*}{ Economics } & macroeconomics & macro (big) & macroscopic \\
\cline { 2 - 4 } & microeconomics & micro (small) & microwave, microscope \\
\hline Science & hydroelectric & hydro (water) & hydrology, hydrate \\
\hline Law & jurisdiction & ius (law) & jurisprudence \\
\hline
\end{tabular}

Equally useful is to exploit the function of morphemes like er, for example in "learner", where the morpheme -er implies the meaning of "s/he who learns". Also prefixes and suffixes play an important role in terms of facilitating the understanding of the meaning of words: prefixes such as il- (i.e. illegal), un- (i.e. uninominal), no (i.e. no one), or suffixes such as -less (i.e. penniless), -ful (i.e. plentiful). Word families represent an equally useful means to clarify meaning: from the word "load" many others can stem, including "loader", "loading", "unload", "upload", "overload".

\section{Key theoretical principles}

Below is a list of some essential theoretical principles representing the core of this article. Any educator should know at least the meaning of the following theoretical pairs and triples, which imply the theoretical competence necessary for the self-conscious implementation of strategies, techniques, activities, skills, necessary to fulfill the required widely-shared aims and objectives in any educational context from elementary school to university.

- cognitive vs affective vs psychomotor domains

- competence vs performance
- didactics vs mathetics vs glottodidactics

- error vs mistake

- exercise vs activity

- form vs content

- formative vs summative assessment/evaluation

- inductive vs deductive method

- langue vs parole - signified vs signifier

- latent vs manifest curriculum

- learning vs teaching

- intelligence vs intelligencies

- mark vs statement

- mock vs formal examination

- mother tongue (L1) vs the second language (L2) vs foreign language (FL)

- notion vs function

- product vs process

- left vs right hemisphere

- socio/vs psycho/vs neurolinguistics

- text vs hypertext

- theory vs practice

- token vs value

- use vs usage. 


\author{
E-ISSN: 2469-6501 \\ VOL: 7, ISSUE: 10 \\ October/2021 \\ DOI: http://dx.doi.org/10.33642/ijbass.v7n10p2

\section{Cognitive vs affective vs psychomotor domains}

The cognitive domain is the ability to perceive, order, sequence, handle information; it expresses preferences for spontaneous learning or planned studies and distinguishes a person's learning style preferences. The main mental operations, in order of difficulty, ${ }^{4}$ include:

1. knowledge: learning/acquiring information

2. comprehension: ordering information

3. application: applying knowledge for solving problems

4. analysis: identifying mistakes in a text

5. synthesis: drawing the plan of a house following the information in a text

6. evaluation: i.e. You can't believe everything you read online is true. Do you ever doubt anything? Do you ever double-check? How?

The affective domain refers to motivation, feelings, sensations, attitudes, levels of relationships, managing success or failure, while the psychomotor domain deals with skills learning and/or acquisition and their development, favorite contents, preferred modes of presentations, actions, and movements required in the learning environment. Competence vs performance

Linguistic competence is the system of linguistic knowledge possessed by the educated native speakers of a language. It is distinguished from linguistic performance, which is the way a language system is used in communication. Noam Chomsky ${ }^{5}$ introduced this concept in his elaboration of generative-transformational grammar, where it was widely adopted. According to Chomsky, competence is the ideal language system that enables speakers to produce and understand an infinite number of sentences in their language, using a finite number of items, and to distinguish grammaticalcorrect sentences from ungrammatical ones.

\section{Didactics vs Mathetics vs Glottodidactics}

These words belong to an equally significant area of education that requires special attention to grant everybody lifelong learning opportunities. What do these three words mean? In the Italian educational scenario, the word «didattica» is often abused, frequently remaining unclear, therefore it is essential to disambiguate its meaning especially during this period of the pandemic. Politicians and administrators, teachers and professors, students and parents alike use this word as a label for lectures, lessons, timetables, syllabi, online distance learning, face-to-face learning, and so on. However, a greater precision is much needed and didactics should be given back its true meaning: «a way, a mode of working both on the theory and practice of learning and teaching». This makes clear that learning should be included in the meaning of didactics with all its consequent formative implications.

To disambiguate the meaning of this word we should start by saying that it has more than one meaning; we should distinguish at least its dual meaning: in a wide sense, a theory and practical application of teaching and learning. Differently from mathetics (the science of learning), didactics refers also to the science of teaching. The main functions of didactics are: cognitive because it favors learning and acquiring knowledge; formative, as it helps developing skills, abilities, competencies; instrumental because it aims at achieving educational goals.

Regarding glottodidactics, it is a mix of pedagogy, psychology, and linguistics. This discipline analyzes and puts into practice theoretical assumptions, strategies, methods, and techniques for language learning and teaching. It is also defined as a "theoretical-practical" discipline. Mathetics ${ }^{6}$, instead, is the science of learning.

\section{Error vs mistake}

When you say "Yesterday, I go* to work", you know you should have said, "went": you just made a mistake or a slip of tongue. An error is, instead, something you are not aware of; it may depend on syntax, morphology, glossary, idiomatic usage you have not learned or acquired yet. Identifying, analyzing, and correcting errors gives the learner the chance to learn something new. An error of overgeneralization, usually made by kids, is "Yesterday I goed* to school by bus". Exercise vs activity

An exercise is a drill, a learning/teaching procedure that involves controlled, guided, or open-ended practice of some aspect of language. The term activity is more general and refers to any kind of purposeful classroom procedure that involves learners doing something that relates to the goals of the course. For example, singing a song, answering/asking a question, reacting to visuals, listening to sound stimuli, playing a game, taking part in a debate, having a group discussion, are all different kinds of learning and teaching activities; it is something that freely, consciously or unconsciously activates the learner's brain, heart and/or foot.

\section{Form vs content}

Content is what an oral or written text says. The form is how what it says is arranged.

\section{Formative vs summative assessment/evaluation}

Formative assessments and summative assessments are both essential parts of any curriculum map/route. But what do they mean? Formative assessments are tests that assess how someone is learning material throughout a course. Summative assessments evaluate how much someone has learned throughout a course. In the lecture/classroom, formative assessments take place during a course and summative assessments are the final evaluations at the end of the course.

\section{Inductive vs deductive method}

The main difference between inductive and deductive reasoning is that the former aims at discovering and/or ${ }^{6}$ The term was coined by John Amos Comenius (1592-1670) in his work Spicilegium didacticum, published in 1680. He understood
Mathetics, the science of learning as the opposite of Didactics, the science of teaching. Mathetics considers and uses findings of curren interest from pedagogical and cognitive psychology, neurophysiology, sociolinguistics, and information technology. More recently, Seymour Papert (1993), mathematician, educator and essayist, from MIT, has paid attention to this word, which comes from the Greek term mathēmatikos: willing to learn. 


\author{
E-ISSN: 2469-6501 \\ VOL: 7, ISSUE: 10 \\ October/2021 \\ DOI: http://dx.doi.org/10.33642/ijbass.v7n10p2 \\ (c) $\underset{B Y}{(i)}$ \\ https://creativecommons.org/licenses/by/4.0/
}

developing a theory while the latter aims at testing an existing theory. Inductive reasoning moves from specific observations to broad generalizations and deductive reasoning the other way round.

\section{Langue vs parole -Signified vs signifier}

Parole means "speech". De Saussure, on the other hand, meant by it both the written and spoken language as experienced in everyday life; it is the precise utterance and use of langue. Therefore, "parole", unlike "langue", is as diverse and varied as the number of people who share a language and the number of utterances and attempts produced to use that language. The part De Saussure calls the 'sound-image is also called the signifier: the sound of the word learner creates in our minds. The signifier connects learner to its pronunciation. De Saussure named the meaning of the sign signified. The signified connects the meaning to the mental world (more simply, in speaking and listening /13:nər/, the signifier, becomes the signified: 'a person who is finding out about a subject or how to do something).

\section{Latent vs manifest curriculum}

The manifest curriculum is the content learners are expected to learn, the latent or hidden curriculum, instead, refers to the values, beliefs, and attitudes that students learn and/or acquire also through the education system; this is the knowledge that becomes more deeply embedded in students' memories and daily interactions, while the content is not what students remember most; for example, a latent function of a curriculum is that it helps socialize young individuals to form a more cohesive group, while a manifest function is, for example, remembering L. Bloom's biographical data.

\section{Learning vs teaching}

The focus is on the learner or the teacher. Learners' participation and involvement appear facilitated when focusing on them. Learning is a continuous process for every one of us. In a perfect world, we all learn something new every day. While we see formal education as a necessity to learning, there will always be various ways to learn. Teaching is just a more formal approach to giving lessons/lectures with learning as the result.

Learning is a conscious process, whereby you exploit all the known strategies and techniques to add new information to your encyclopedia, usually through studying; instead, acquisition happens unconsciously.

We, as teachers, don't teach; we may only create the correct conditions for learning to take place. The learning/teaching process has to be student-centered, not teacher-dominated, inquiry-based, participatory, linked to one's own experience. We learn if we are able and allowed to raise questions, provide answers, make hypotheses, discuss with peers and teachers, reflect on results, apply the acquired skills and competencies to real-world situations, respecting the way our brain works, and cooperating with it. The main objective of any learning/teaching environment is to equip students with skills and competencies to be spent successfully in real life; for example, being able to reflect on errors of any kind is an irremissible life skill. ${ }^{7}$

\section{Intelligence vs intelligences}

A great deal of intelligence can be invested in ignorance when the need for illusion is deep.

\section{Saul Bellow, To Jerusalem and Back}

Merriam Webster's Dictionary defines intelligence as:

(1) the ability to learn or understand or to deal with new or trying situations;

(2) the ability to apply knowledge to manipulate one's environment or to think abstractly as measured by objective criteria (such as tests).

It is relevant to point out that "Anything worth teaching can be presented in many different ways: these multiple ways can make use of our multiple intelligences", in Howard Gardner's words. Gardner has introduced eight different types of intelligence so far: logical/mathematical, linguistic, musical, spatial, bodily-kinesthetic, naturalist, interpersonal and intrapersonal. ${ }^{8}$ The linguistic and logicalmathematical modalities are highly valued in school and society, but there may be other intelligence (i.e. spiritual, existential and moral intelligence) too; all of them play an equally important role in the educational process.

\section{Mark vs statement}

In Italian universities marks range from 1 to 30 cum laude; 18 out of 30 is the lowest pass mark, while in primary and secondary school's marks range from 1 to 10 and are often coupled with "excellent", "very good", "good", "sufficient", "poor", "very poor". General statements and other forms for assessing competencies are not used at academic levels in Italy.

\section{Mock vs formal examination}

Mock exams are highly popular in the United Kingdom; marking them may or may not count, and they serve chiefly as practice for future exams so that the teachers can set an unofficial grade before the end of term. The advantages of mocks are numerous and very important for students. They can face the actual difficulties of official tests, calculating the time necessary to complete the activities; in addition, mocks release anxiety.

Mother tongue (L1) vs the second language (L2) vs foreign language (FL)

A first language is the mother tongue or native language of a person while a second language is a language that is not her/his native one, but it has been learned to communicate with the native speaker of that language in daily life, implying that it is spoken in the place where a person lives. One could say that immigrants or ethnic minorities in a certain country will be learning this language as their second language. A foreign language is a language studied at school and not widely and fluently spoken in that place.

Pepicelli, E., in Intorcia E., Pepicelli E., English For Me, Aracne, Roma, 2017. 


\author{
E-ISSN: 2469-6501 \\ VOL: 7, ISSUE: 10 \\ October/2021 \\ DOI: http://dx.doi.org/10.33642/ijbass.v7n10p2 \\ (c) $\rightarrow$ \\ https://creativecommons.org/licenses/by/4.0/
}

A foreign language is a language a person learns because $\mathrm{s} / \mathrm{he}$ is interested in it for whatever reason. An Italian family living in Bozen has Italian as their mother tongue, German as their second language, and English (if it is studied at school) as a foreign language. Instead, for an Austrian family living in Bozen, German is their mother tongue, Italian their second language, and English, if studied at school, their foreign language. French in the Valle d'Aosta is another relevant example in Italy, this time with the French language instead of German.

\section{Notion vs function}

A notion is a mental idea, a concept, while the function is what something does or is used for. The notion comes before function, i.e. in the development of human society, men made the wooden wheel (notion/langue/use/token as differently identified by some linguists in time), and only later they called it by different names, depending on the place, and/or other circumstances ("wheel" in English, "rad" in German, "rota" in Latin, "ruota" in Italian, "roue" in French, "koleso" in Slovak, "tekerlek" in Turkish, etc.).

Some examples of language functions are: asking for information, giving information, accepting, refusing.

\section{Product vs process}

A process is a series of steps designed to lead to a particular outcome or goal. A product is the outcome or goal of a process. In terms of education, you could say that process is how learning happens and the product is what has been learned.

\section{Left vs right hemisphere}

Some topics and relevant terminology connected with the human brain and its working include: right and left hemispheres, right/left dominance, global vs analytic behaviors, divergent thinker vs convergent thinker, mind maps, stream of consciousness, brainstorming.

A left-brained person, for instance, enjoys thinking, loves order, and is very good at analysis, is logical, objective, planned, discriminative, quantitative. If, on the other hand, you are creative, subjective, impulsive, emotional, imaginative, holistic, you are a right-brained person. The ideal situation is a balance between the two hemispheres, in so far as it will produce the best results as far as learning is concerned. The non-linearity (i.e. stream-of-consciousness approach through brain-storming activities) shows the way the human brain works.

\section{Sociolinguistics vs psycholinguistics vs neurolinguistics Sociolinguistics}

It deals basically with the relationship between language and society. Thanks to its dual focus, sociolinguistics is considered a branch of both linguistics and sociology. Sociolinguistics suggests getting learners involved through a large variety of activities, such as brainstorming and dictocomp; it means working together and sharing information, sensations, feelings, lowering the affective filter to create a relaxed and relaxing atmosphere, also guiding learning and favoring acquisition, reflecting on the media (i.e. distance learning and its social implications).

\section{Psycholinguistics}

Psycholinguistics or psychology of language is the study of the psychological and neurobiological factors that enable humans to acquire, learn, use, understand and produce language. It explores the mental structures and processes involved in the acquisition and use of language. ${ }^{9}$ Psycholinguistics implies also the knowledge and ability to implement some basic psychological principles such as each learner wishes to be in the limelight anyway starting from what is closer to her/him; from a psychological point of view, the sun is nearer than the chlorophyll function. The objective/s of any activity learners are involved in, should be clear to them well in advance.

\section{Neurolinguistics}

Neurolinguistics is the study of how language is represented in the brain, focusing on what happens in our brains as we acquire that knowledge, and what happens as we use it in our everyday lives. Brain means, in this context, mainly cognitive activities and intelligence.

\section{Text vs hypertext}

A hypertext term coined by Ted Nelson around 1965 is a text which is not constrained to be linear, page after page, but contains links to other texts. It can include graphics, images and sounds, diagrams, drawings.

\section{Theory vs practice}

This represents an unavoidable blending in the learning/teaching process. Why the emphasis on theory? To avoid exaggerated empiricism. It is important to find out the theoretical foundations of any activity in the class/lecture room and at home through reflection.

A simple definition of theory defines it as an idea or mental plan of the way to do something, while by practice we mean doing something frequently or customarily, either for instruction, profit, or amusement (Webster's dictionary).

\section{Token vs value}

Tokens are words, chunks, structures, sentences, while value is always negotiated between listener and speaker or between reader and writer; the value changes depending on the context, situation, cultural level, age, time, place, and other variables (C. Brumfit, 1983).

\section{Use vs usage}

These terms are used in linguistics in contrast to one another to describe ways in which a person knows and uses language. In usage, a person knows about language or items in language abstractly as a component in a language system. In use, a person knows how to use language for communication. This distinction, which focuses on the difference between knowing about language (usage) and knowing how to use language

${ }^{9}$ The titles we chose for our textbooks (namely, My English Workbook, English for Success, Relevant Notes for Students of English at the University of Sannio, New English for Success, English for Me, My English Practice Booklet) aim at involving affectively each learner from the very start, through the use of possessives, personal pronouns, beginning with the front pages and with the forewords addressed to them, at times in Italian, their mother tongue ("Dear Students", "Carissime/i Studentesse e Studenti") 


\author{
E-ISSN: 2469-6501 \\ VOL: 7, ISSUE: 10 \\ October/202 1 \\ DOI: http://dx.doi.org/10.33642/ijbass.v7n10p2

(use), was critical in the development of language teaching, away from the grammar-translation method and towards a functional-communicative-cooperative approach. Henry Widdowson introduced and developed this distinction in 1978.

\section{Reflecting on translation}

In the interplay between two (or even among more) languages, special relevance is acquired by translation, meant as the process of turning something - for instance a text - into one's or another language, or from one language into another one. This is important in any educational context, first of all, because any person, when communicating in his/her mother tongue, orally or in writing, thinks in her/his mother tongue, unless s/he is bilingual when it is an automatic process.

In foreign language learning, translation was considered so important until the Sixties to give the name to the «grammar-translation method». Students had to learn the grammar rules of the target language and then they had to apply them: as a result, although they knew the rules of the target language, they were unable to use it to communicate, to render the exact meaning through spoken or written acts, and equally unable to add their meaning, enriched, varied by their experience of life and studies. Any person gives each word a personal and unique meaning, to the extent that any interlocutor has to negotiate the exact meaning of each spoken or written act.

For every learner, it is easier to translate from the target language into her/his mother tongue, but only a perfect bilingual can judge the level of correctness of the translation and perceive to what extent the original meaning has been limited or interfered within the whole process.

When in the Seventies a new approach became popular, the so-called «notional-functional-communicative approach», grammar was literally ignored and even rejected; it became unimportant and translation was ignored and put in its correct place by both theorists and educators. Grammar's goal is to ensure the correctness of any language act phonetically, syntactically, morphologically, orthographically (syntax, morphology, spelling, phonology).

From then on communication has remained the irreplaceable objective of any educational approach, granting grammar its descriptive role rather than the prescriptive one; but, as it happens for any excess in whatever field of knowledge, translation in the last fifty years has recovered its role in the learning/teaching approach to languages. Learners think in their mother tongue and then try to translate it into a foreign language unless they are operating in a second language context, where the situation can be that of bilingualism. To be a perfect bilingual person, since birth, a child should have her/his mother as a perfect bilingual who has to communicate with her/him every day in both languages or they should live, let us say, six months in France and six months in Italy, for a rather long period.
Now it is important also to say that translation is very important in any learning/teaching approach, keeping well in mind that nothing can be perfectly translated from one language into another as it is impossible that the various meanings deriving from all the nuances related to the context, education, and many additional, relevant variables that can be covered from the single word in another language, can be captured, apart from its basic meaning. To support this statement, it is sufficient to consider the idiomatic uses, the phraseology, the proverbs and sayings, the collocation of that word both in the mother tongue and in the target language. There is no perfect coinciding, no semantic overlapping between a word and its use and usage in two languages. They cannot coincide, but the action of translating, notwithstanding this limitation, has proved to be a very useful and rewarding tool.

In conclusion, translation is important, useful, and necessary in some contexts because it helps anyone to communicate with someone else unless both are perfectly bilingual. It is also necessary to distinguish translation from the mother tongue into a foreign language and vice versa; mother tongue into a second language and vice versa.

\section{Conclusions}

The above-mentioned issues seem to refer specifically to the areas of languages that are important for any subject. If implemented correctly, they facilitate learning and acquisition in general. Everybody knows how difficult it is even to master one's mother tongue at certain levels also by educated people. All the language areas are equally important: phonetics, morphology, syntax, glossary and idioms, figures of speech, such as hyperbole, simile and metaphor, denotation, connotation, and so on.

As mentioned before, another area extremely relevant to our discourse is microlanguages, that is vocabulary related to a specific subject, be it law or French, civil engineering or archeology, physics or astronomy, music or IT, science or math's, politics or tourism. In an oral or written discourse, the appropriateness of vocabulary becomes paramount.

Unfortunately, many people involved in education know near to nothing when referring to the theory behind the practice. When operating these people risk falling into an excess of practicism, which is a rather negative mode.

In the process of learning and teaching, experience is important, practice as well, without forgetting theory. Before entering a class or lecture room, everybody should be trained to acquire the necessary theory to manage adequately any educational environment. In addition, every educator should ask her/himself: "Why am I implementing this strategy, technique, activity?". To this purpose, there are courses held by specialists, books, multimedia materials, articles, and research which are of great help and make it possible to face a group of learners with sufficient intellectual honesty and tranquility. 


\section{References}

Bellah, N. R. (ed.), Emile Durkheim on Morality and Society, University of Chicago Press, 1975.

Bloom, B. S.; Engelhart, M. D.; Furst, E. J.; Hill, W. H.; Krathwohl, D. R. (1956). Taxonomy of educational objectives: The classification of educational goals. Handbook I: Cognitive domain. New York: David McKay Company.

Finocchiaro, M., B., Brumfit. C., The Basis of a Communicative Methodology in Language Teaching, Thesis submitted for the Degree of Doctor of Philosophy of the University of London, Institute of Education, 1983.

Chomski, N., Aspects of the Theory of Syntax, M.I.T. Press, 1965.

Coyle, D., Hood, P., CLIL: Content and Integrated Language Learning, O.U.P., 2010.

De Saussure, F., Cours de Linguistique Générale, 1916.

Finocchiaro, M., B., Brumfit, C., The Functional Notional Approach: From Theory to Practice, 2012, O.U.P., USA (first published April 1st 1983).

Gardner, H., Multiple Intelligences: New Horizons in Theory and Practice, New Horizons, 2006.

Hoidn, S., Klemenčič, M. (eds.), The Routledge International Handbook of Student-centered Learning and Teaching in Higher Education, 2021, Routledge, 2 Park Square, Abingdon, Oxon.

Intorcia, E., Pepicelli, E., English for Me, Aracne, Rome, 2017.

Lyons, J., Chomski, Fontana, 1972.

Oakeshott, M., "Education: the Engagement and its Frustration”, in Fuller, T., (ed) (1989), The Voice of Liberal Learning, New Haven and London: Yale University Press.

Pepicelli, E., "Student-Centered Learning and Teaching Processes (SCLTPs): Old Assumptions and New Approaches", International Journal of Business and Applied Social Science (IJBASS) E-ISSN: 2469-6501, Vol. 7, Issue 1 January 2021, DOI: https://doi.org/10.33642/ijbass.v7n1p1

Pepicelli, E., "PSLS. A Second Level Course: Analysis and Perspectives", in Problems and Experiences, n.1, 26-29, Oxford University Press, La Nuova Italia, 1986.

Widdowson, H, Disciplinarity and Disparity in Applied Linguistics, BAAL, Leeds, 2017.

\section{Sitography}

https://doi.org/10.2307/2089531

https://en.wikipedia.org/wiki/Content and_language_integrated_learning

https://www.jstor.org/stable/208953

https://www.retrievalpractice.org/why-it-works

http://www.unric.org/it/ 